\title{
Enhanced Spontaneous Transmitter Release Is the Earliest Consequence of Neocortical Hypoxia That Can Explain the Disruption of Normal Circuit Function
}

\author{
Ilya A. Fleidervish, ${ }^{1}$ Christine Gebhardt, ${ }^{2}$ Nadav Astman, ${ }^{3}$ Michael J. Gutnick, ${ }^{1}$ and Uwe Heinemann ${ }^{2}$ \\ ${ }^{1}$ Koret School of Veterinary Medicine, The Hebrew University of Jerusalem, Rehovot, Israel 76100, 2 Department of \\ Physiology, Humboldt University, D10117 Berlin, Germany, and 3Zlotowski Center for Neuroscience, Faculty of Health \\ Sciences, Ben-Gurion University of the Negev, Beersheva, Israel 84105
}

\begin{abstract}
After the onset of an acute episode of arrested circulation to the brain and consequent cerebral hypoxia, EEG changes and modifications of consciousness ensue within seconds. This in part reflects the rapid effect of hypoxia on the neocortex, where oxygen deprivation leads to impaired neuronal excitability and abnormal synaptic transmission. To identify the cellular mechanisms responsible for the earliest changes in neocortical function and to determine their time course, we have used patchin-slice recording techniques to investigate the effects of acute hypoxia on the synaptic and intrinsic properties of layer 5 neurons. Coronal slices of mouse somatosensory cortex were maintained at $37^{\circ} \mathrm{C}$ and challenged with episodes of hypoxia (3-4 min of exposure to $95 \% \mathrm{~N}_{2}, 5 \% \mathrm{CO}_{2}$ ). In recordings with cell-attached patch electrodes, activation of ATP-sensitive potassium channels first became detectable $211 \pm 11 \mathrm{sec}$ (range,
\end{abstract}

$185-240 \mathrm{sec} ; n=6$ patches) after the onset of hypoxia. Similar recording techniques revealed no alterations in the properties of $\mathrm{Na}^{+}$currents in the first 4 min after the onset of hypoxia. The earliest hypoxia-induced disturbance was a marked increase in the frequency of spontaneous EPSCs and IPSCs, which began within 15-30 sec of the removal of oxygen. This rapid synaptic effect was not sensitive to TTX and was present in $\mathrm{Ca}^{2+}$-free perfusate, indicating that the hypoxia had a direct influence on the vesicular release mechanisms. The incoherent, massive increase in miniature PSCs would be expected to deplete the readily releasable pool of vesicles in cortical terminals, and to thereby markedly distort the neuronal interactions that underlie normal circuit function.

Key words: hypoxia; neocortex; transmitter release; miniature EPSC; miniature IPSC; $\mathrm{Na}^{+}$current; $\mathrm{K}_{\text {ATP }}$ channel
Five decades ago, Rossen et al. (1943) demonstrated the remarkable speed with which oxygen deprivation can influence the normal function of the neocortex. In an extraordinary series of experiments, they showed that after sudden, complete arrest of blood flow to the human brain, unconsciousness ensues within 4-10 sec and that complete recovery of cortical function occurs over a similarly rapid time course. The seconds required to achieve a marked disruption of function are much briefer than the minutes required until the appearance of the first histopathological evidence of neuronal damage (Hara et al., 1993; Lipton, 1999). It is thus apparent that the earliest effects of oxygen deprivation entail a rapid and reversible influence on one or more of the complex excitability and synaptic mechanisms that combine to achieve normal cortical circuit function (Kandel and Schwartz, 1985). Modern studies using isolated neurons and in vitro slice preparations have investigated the cellular mechanisms that may underlie these functional disturbances (Fujiwara et al., 1987; Leblond and Krnjevic, 1989; Jiang and Haddad, 1992; Luhmann and Heinemann, 1992; Cummins et al., 1993; Katchman and Hershkowitz, 1993; Fujimura et al., 1997; Erdemli and Crunelli, 1998; Hammarstrom and Gage, 1998; Mironov and Richter, 1999;

Received Jan. 16, 2001; revised March 20, 2001; accepted April 18, 2001.

This research was supported by a grant from the German-Israeli Foundation for Scientific Research and Development, by the Sonderforschungsbereich 507, and by the Bundesministerium für Bildung, Wissenschaft, Forschung, und Technologie.

Correspondence should be addressed to Ilya A. Fleidervish, Koret School of Veterinary Medicine, The Hebrew University of Jerusalem, P.O. Box 12, Rehovot 76100, Israel. E-mail: fleider@agri.huji.ac.il.

Copyright (C) 2001 Society for Neuroscience $0270-6474 / 01 / 214600-09 \$ 15.00 / 0$
Kulik et al., 2000). In studies of neocortical circuitry, acute hypoxia has been shown to induce a rapid deterioration of action potential-dependent synaptic transmission (Luhmann and Heinemann, 1992; Cummins et al., 1993), the precise ionic and molecular mechanisms of which remain unclear. At least three plausible hypotheses have been suggested by recent literature.

First, it has been hypothesized that a breakdown in communication between neurons occurs because of hypoxia-induced changes in the passive properties of the postsynaptic membrane (Hansen et al., 1982; Fujiwara et al., 1987; Leblond and Krnjevic, 1989; Luhmann and Heinemann, 1992), as potassium channels whose activation is normally prevented by the presence of ATP (Zhang and Krnjevic, 1993; Jiang et al., 1994; Fujimura et al., 1997; Pelletier et al., 2000) open, causing a marked decrease in input resistance and consequent impairment of synaptic integration in the somatodendritic compartment (Hansen et al., 1982; Luhmann and Heinemann, 1992). Second, the deleterious effects of hypoxia on neocortical function might reflect a reduction in neuronal ability to initiate and propagate action potentials, because of a decrease in $\mathrm{Na}^{+}$channel availability (Cummins et al., 1993; O’Reilly et al., 1997; Mironov and Richter, 1999). Third, oxygen deprivation might preferentially target presynaptic $\mathrm{Ca}^{2+}$ currents (Krnjevic and Leblond, 1989; Young and Somjen, 1992) or the vesicular release machinery (Katchman and Hershkowitz, 1993; Kulik et al., 2000). The present investigation was designed to explore these possibilities in layer 5 of the mouse neocortex. Using whole-cell and cell-attached configurations of the patch-inslice technique, we now report that the earliest consequence of acute hypoxia is an effect on the synapse that is manifested by a 
marked increase in the rate of spontaneous release, that this precedes subsequent activation of ATP-sensitive potassium channels by $>2$ min, and that no early effect on $\mathrm{Na}^{+}$channel availability is seen under these experimental conditions.

\section{MATERIALS AND METHODS}

Slice preparation and maintenance. Experiments were performed in 400$\mu \mathrm{m}$-thick coronal slices of somatosensory cortex of CD-1 mice that were 14-24 postnatal days of age. Procedures for preparation and maintenance of slices were similar to those described previously (Fleidervish et al., 1996, 1998). Animals of either sex were deeply anesthetized with Nembutal $(60 \mathrm{mg} / \mathrm{kg})$ and killed by decapitation; their brains were rapidly removed and placed in cold $\left(6^{\circ} \mathrm{C}\right)$, oxygenated $\left(95 \% \mathrm{O}_{2}-5 \%\right.$ $\mathrm{CO}_{2}$ ) artificial CSF (aCSF). Coronal slices from a region corresponding to the primary somatosensory cortex were cut on a vibratome (Series 1000; Pelco International, Redding, Canada) and placed in a holding chamber containing aCSF at room temperature; they were transferred to a recording chamber after $>1 \mathrm{hr}$ of incubation.

Patch-clamp recording. Slices were maintained in a small $(300 \mu \mathrm{l})$ interface-type recording chamber (Haas et al., 1979), and a "blind" patch-clamp technique (Hamill et al., 1981; Blanton et al., 1989) was used to record either $\mathrm{Na}^{+}$and $\mathrm{K}^{+}$single-channel currents or transmembrane potential and currents from layer 5 neurons. Single-channel openings were recorded in a cell-attached configuration, and whole-cell current was recorded in a whole-cell configuration using an Axopatch 1D amplifier (Axon Instruments, Foster City, CA). Transmembrane potential was recorded in a whole-cell configuration using an Axoclamp-2B amplifier (Axon Instruments) in bridge mode. Patch pipettes were manufactured from thick-walled borosilicate glass capillaries $(1.5 \mathrm{~mm}$ outer diameter; Hilgenberg, Malsfeld, Germany) and had resistance of 1.5-3.5 M $\Omega$. For cell-attached recordings, pipettes were coated to within $\sim 100 \mu \mathrm{m}$ of the tip with Sylgard (Dow Corning, Midland, MI). All recordings were made at $37 \pm 1^{\circ} \mathrm{C}$.

Command voltage protocols were generated, and single-channel data were acquired on-line with an Axolab 1100 analog-to-digital interface. Data were low-pass-filtered at $2-5 \mathrm{kHz}(-3 \mathrm{~dB}$, four-pole Bessel filter) and digitized at $10-20 \mathrm{kHz}$. For $\mathrm{Na}^{+}$channel recordings, capacitative and leak currents were reduced before data acquisition using the built-in circuits of the amplifier. Null traces for digital subtraction of remaining capacitative and leak current components were produced by stepping from a depolarized membrane potential, at which all $\mathrm{Na}^{+}$channels in the patch were inactivated. For whole-cell voltage-clamp recording, care was taken to maintain membrane access resistance as low as possible (usually 3-4 $\mathrm{M} \Omega$ and always $<10 \mathrm{M} \Omega$ ); series resistance was $80 \%$ compensated using the built-in circuitry of the amplifier. Data were low-pass-filtered at $2 \mathrm{kHz}(-3 \mathrm{~dB}$, four-pole Bessel filter) and sampled at a $5-10 \mathrm{kHz}$ digitalization frequency. For whole-cell current-clamp recordings, data were low-pass-filtered at $10 \mathrm{kHz}(-3 \mathrm{~dB}$, single-pole filter), stored on video tape, and digitized off-line at up to $20 \mathrm{kHz}$.

Solutions. The aCSF contained (in $\mathrm{mM}$ ): $124 \mathrm{NaCl}, 3 \mathrm{KCl}, 2 \mathrm{CaCl}_{2}, 2$ $\mathrm{MgSO}_{4}, 1.25 \mathrm{NaH}_{2} \mathrm{PO}_{4}, 26 \mathrm{NaHCO}_{3}$, and 10 glucose, $\mathrm{pH} 7.3$, at $37^{\circ} \mathrm{C}$ when bubbled with a $95 \% \mathrm{O}_{2}-5 \% \mathrm{CO}_{2}$ mixture. The pipette solution for single-channel $\mathrm{Na}^{+}$experiments contained (in mM): $130 \mathrm{NaCl}, 3 \mathrm{KCl}, 2$ $\mathrm{CaCl}_{2}, 2 \mathrm{MgCl}_{2}, 10$ glucose, 5 TEA-Cl, 14 -AP, and $10 \mathrm{HEPES}$ (sodium salt), $\mathrm{pH}$ 7.3. The pipette solution for single-channel $\mathrm{K}^{+}$experiments contained (in mM): $135 \mathrm{KCl}, 2 \mathrm{CaCl}_{2}, 2 \mathrm{MgCl}_{2}, 10$ glucose, and 10 HEPES (potassium salt), $\mathrm{pH}$ 7.3. The pipette solution for whole-cell voltage-clamp experiments contained (in $\mathrm{mM}$ ): $135 \mathrm{Cs}$ gluconate, $6 \mathrm{CsCl}$, $2 \mathrm{MgCl}_{2}$, and 10 HEPES (cesium salt), pH 7.25; QX-314 (Alamone Labs, Jerusalem, Israel) was routinely added to the pipette solution to avoid $\mathrm{Na}^{+}$current-mediated escapes from voltage clamp. The pipette solution for whole-cell current-clamp experiments contained (in $\mathrm{mM}$ ): $135 \mathrm{~K}$ gluconate, $6 \mathrm{KCl}, 2 \mathrm{MgCl}_{2}$, and $10 \mathrm{HEPES}$ (potassium salt), $\mathrm{pH} 7.25$.

Induction of hypoxia. Hypoxic episodes were produced by switching the gas flow over the slice from $95 \% \mathrm{O}_{2}-5 \% \mathrm{CO}_{2}$ to $95 \% \mathrm{~N}_{2}-5 \% \mathrm{CO}_{2}$, as first described by Leblond and Krnjevic (1989). Because the experiments were performed in an interface-type chamber, in which slices are separated from the aerating gas atmosphere by a thin film only, we anticipated that, after the onset of a hypoxic episode, the partial pressure of $\mathrm{O}_{2}$ would drop abruptly throughout the slice, and the effective equilibrium between the atmosphere and slice would be achieved within several seconds. Direct measurement of the $\mathrm{pO}_{2}$ in the gas phase of the interface chamber (ISO2; World Precision Instruments, Sarasota, FL) showed that it reaches a steady value of $6 \pm 2$ torr during hypoxia. Within the brain tissue, $\mathrm{pO}_{2}$ could be even lower because of the oxygen consumption by neurons and glial cells.

The hypoxic episode duration was kept within 3-5 min to prevent a spreading depression-like anoxic depolarization (Luhmann and Heinemann, 1992), which occurs if hypoxia lasts for $>5 \mathrm{~min}$. To avoid irreversible cumulative damage, we produced no more than three hypoxic episodes in the same slice, with the intervals between them $>40$ min. Only one hypoxic episode per cell was evaluated.

Data analysis. Data averaging, digital subtraction of null traces, and current-peak detection were made using pClamp 5.5 software (Axon Instruments) and Mini Analysis program 4.0 (Synaptosoft, Leonia, NJ). Data were fitted using Origin 3.78 (OriginLab, Northampton, MA). If not otherwise noted, values are given as mean \pm SD. For statistical analysis, a Student's $t$ test was performed.

\section{RESULTS}

The effects of short-term hypoxia on $\mathrm{Na}^{+}$and $\mathrm{K}^{+}$channel properties and on spontaneous synaptic events were studied in a total of 64 neurons that showed recovery of effects after a hypoxic period.

\section{Activation of ATP-sensitive potassium channels and neuronal input resistance}

Previous studies have shown that ATP-sensitive potassium $\left(\mathrm{K}_{\mathrm{ATP}}\right)$ channels are present at high density in the membranes of the central neurons (Mourre et al., 1989; Xia and Haddad, 1991; Karschin et al., 1997; Pelletier et al., 2000) and that their activation is a major cause of hypoxic hyperpolarization, a decrease in neuronal input resistance, and a decrease in excitability (Zhang and Krnjevic, 1993; Jiang et al., 1994; Fujimura et al., 1997).

We used cell-attached recordings to determine the time course of $\mathrm{K}_{\mathrm{ATP}}$ channel activation during hypoxia. To ease channel detection, pipettes contained $135 \mathrm{~mm} \mathrm{KCl}$, so that $E_{\mathrm{K}}$ would be close to zero, and the patches were held at $-20 \mathrm{mV}$ relative to resting membrane potential $\left(V_{\mathrm{r}}\right)$ (approximately $-90 \mathrm{mV}$, assuming $V_{\mathrm{r}}$ near $-70 \mathrm{mV}$ ). Patches displaying either no potassium channel activity or only brief background potassium channel openings (Fig. 1 $A$ ) under normoxic conditions were chosen. In the representative experiment illustrated in Figure 1, there was little or no change in the frequency and duration of these openings during the first 2 min after hypoxia onset (Fig. 1B). After 185 sec, a novel type of channel opening appeared, first as rare, single openings or short minibursts (Fig. 1C). Under our experimental condition of near symmetrical $\mathrm{K}^{+}$ion distribution, the reversal potential of these channel openings was $V_{\mathrm{r}}+75 \mathrm{mV}$, and singlechannel conductance was $59 \pm 4 \mathrm{pS}(n=6)$. When the specific $\mathrm{K}_{\text {ATP }}$ channel blocker glibenclamide $(100 \mu \mathrm{M})$ was added to the pipette solution ( $n=3$ patches), these channels were not activated during hypoxia. Activation of $\mathrm{K}_{\mathrm{ATP}}$ channels was quickly reversible with reoxygenation (Fig. $1 D)$. Figure $1 E$ plots the mean $\mathrm{K}^{+}$channel opening frequency for the same patch. It can be seen that the increase in $\mathrm{K}^{+}$channel opening frequency because of activation of $\mathrm{K}_{\mathrm{ATP}}$ channels followed the onset of hypoxia with a significant time lag. Similar results were obtained in recordings from five additional patches; the mean latency for an initially detectable opening of $\mathrm{K}_{\mathrm{ATP}}$ channel was $211 \pm 11 \mathrm{sec}$ (range, 185-240 sec).

Figure $1 F$ shows the effect of hypoxia on apparent input resistance $\left(R_{\text {in }}\right)$, as measured in current-clamp recordings by applying small hyperpolarizing pulses. The decrease in $R_{\text {in }}$ was not the earliest consequence of hypoxia; indeed, $R_{\text {in }}$ did not decrease significantly until $>2$ min after the onset of the hypoxic episode. Although it is likely that activation of $\mathrm{K}_{\mathrm{ATP}}$ channels was largely responsible for the decrease in $R_{\mathrm{in}}$, it is noteworthy that the onset of the resistance change, as measured in a whole-cell configura- 


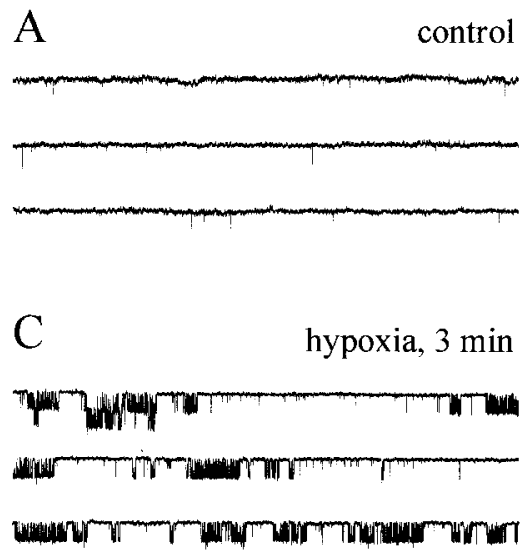

Figure 1. Hypoxia induces activation of ATP-sensitive $\mathrm{K}^{+}$channels with a lag of $\sim 3 \min$. $A$, Under normoxic conditions, a cell-attached recording from a representative layer 5 neuron in a $400-\mu$ m-thick slice maintained at $37^{\circ} \mathrm{C}$ revealed brief, sporadic, "background" openings of potassium channel. The openings are inward because the pipette contained 140 $\mathrm{mM} \mathrm{K}^{+}$, and the membrane was held at a $V_{\mathrm{r}}-20 \mathrm{mV}$ (approximately $-90 \mathrm{mV}$ ). Channel currents were filtered at $2 \mathrm{kHz}$ $(-3 \mathrm{~dB})$ and digitized at $10 \mathrm{kHz} . B$, One minute of hypoxia causes no alteration in the potassium channel activity. $C$, After 3 min of hypoxia, the ATP-sensitive $\mathrm{K}^{+}$ channel began to activate, first as a single openings and minibursts; the frequency and duration of the bursts increased rapidly while hypoxia proceeded. $D$, In this patch, the ATP-sensitive $\mathrm{K}^{+}$channel openings disappear completely only after $10 \mathrm{~min}$ of reoxygenation. $E$, Plot of $\mathrm{K}^{+}$ channel opening frequency before, during, and after a 4 min hypoxic episode. Each dot represents an averaged channel opening frequency during $500 \mathrm{msec} . F$, Changes in neuronal input resistance before, during, and after a $4 \mathrm{~min}$ hypoxic episode.

tion, came slightly earlier than the onset of activation of the potassium conductance, as measured without breaking into the cell. This discrepancy probably reflected an acceleration of the consequences of hypoxia when induced during intracellular dialysis with ATP-free medium. As demonstrated below, additional, synaptic consequences of hypoxia probably also contributed to the decrease in $R_{\text {in }}$.

\section{Early hypoxia does not alter sodium current properties}

It has been reported that hypoxia causes a decrease in $\mathrm{Na}^{+}$ channel availability that is responsible for a rapid decrease in neuronal excitability (Cummins et al., 1993; O'Reilly et al., 1997; Mironov and Richter, 1999). To determine the time course over which these changes develop, we recorded single $\mathrm{Na}^{+}$channels in 12 layer 5 neurons using a cell-attached configuration of the patch-in-slice technique. $\mathrm{Na}^{+}$channels were identified on the basis of their characteristic voltage dependence and conductance. As expected, at physiological temperatures the channel kinetics were faster than at room temperature (Fleidervish et al., 1996). The individual openings were clearly resolvable with a filter bandwidth open to $2-5 \mathrm{kHz}$ (Fig. $2 A$ ). All patches contained multiple channels, as indicated by the appearance of overlapping opening events. In these experiments, we only evaluated patches that contained $>15$ channels, to obtain relatively smooth curves by averaging only 30-150 sweeps (Fig. $2 A$ ). In the cell-attached configuration, the actual membrane voltage is a sum of the command voltage imposed by the experimenter and the resting potential, which is unknown. Unless otherwise noted, we refer to the command voltage in the following text.

Figure $2 A$ shows representative individual $\mathrm{Na}^{+}$channel traces and ensemble $\mathrm{Na}^{+}$current averages during depolarizing pulses to $V_{\mathrm{r}}+50 \mathrm{mV}$ (approximately $-20 \mathrm{mV}$ ) from a holding potential of $V_{\mathrm{r}}$. It can be seen that $4 \mathrm{~min}$ of hypoxia altered neither the amplitude nor the time course of the $\mathrm{Na}^{+}$current, although these
B hypoxia, $1 \mathrm{~min}$

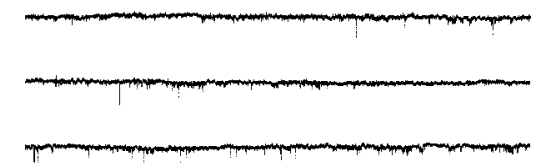

D reoxygenation, $10 \mathrm{~min}$

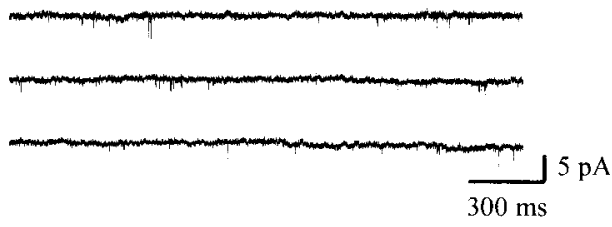

$\mathbf{F}$

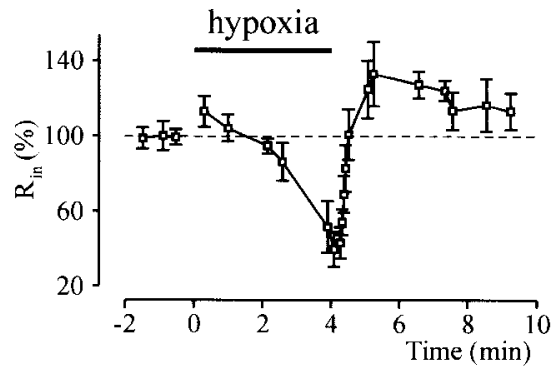

parameters would be extremely sensitive to even a small alteration in $\mathrm{Na}^{+}$channel activation or inactivation. In a different neuron (Fig. $2 B$ ), ensemble $\mathrm{Na}^{+}$currents elicited from a holding potential of $V_{\mathrm{r}}-40 \mathrm{mV}$ (approximately $-110 \mathrm{mV}$ ) were also unchanged after a 4 min hypoxic episode. In the seven neurons we tested, we did not find on average a significant alteration in the voltage-dependence of $\mathrm{Na}^{+}$current activation (Fig. 2C,D) or steady-state inactivation (data not shown). Thus, the voltage of half-activation and the maximal steepness of the activation curve were $36 \pm 2 \mathrm{mV}$ and $6.3 \pm 0.2 \mathrm{mV}^{-1}$, respectively, in the control, and $35 \pm 2 \mathrm{mV}$ and $6.3 \pm 0.2 \mathrm{mV}^{-1}$ at the end of a 4 min hypoxic episode ( $p>0.05 ; n=7$; paired Student's $t$ test). The midpoint and maximal steepness of the inactivation $\left(\mathrm{h}_{\infty}\right)$ curve, determined using a conventional $50 \mathrm{msec}$ prepulse protocol, were $-4 \pm 4 \mathrm{mV}$ and $7.2 \pm 0.4 \mathrm{mV}^{-1}$, respectively, in the control, and $-5 \pm 5 \mathrm{mV}$ and $7.3 \pm 0.4 \mathrm{mV}^{-1}$ after $4 \mathrm{~min}$ of hypoxia $(p>0.05 ; n=7$; paired Student's $t$ test).

The results of these experiments led us to conclude that alterations in $\mathrm{Na}^{+}$channel properties, as described by others (Cummins et al., 1993; O'Reilly et al., 1997; Mironov and Richter, 1999) (but see Hammarstrom and Gage, 1998), apparently occur later in the course of hypoxia, and they cannot account for the very earliest changes in cortical function.

\section{Biphasic effect of hypoxia on spontaneous EPSPs}

Previous studies have shown that in the neocortex, hypoxia quickly and reversibly suppresses both action potential-dependent EPSPs (Luhmann and Heinemann, 1992; Cummins et al., 1993) and spontaneous EPSPs (sEPSPs) (Cummins et al., 1993). However, these studies were done using sharp microelectrode recordings, which do not permit resolution of very small-amplitude spontaneous synaptic events. Here, we examined the effect of hypoxia on sEPSPs using whole-cell current-clamp recordings in neocortical slices. To study the sEPSPs in isolation, neurons were 
A control

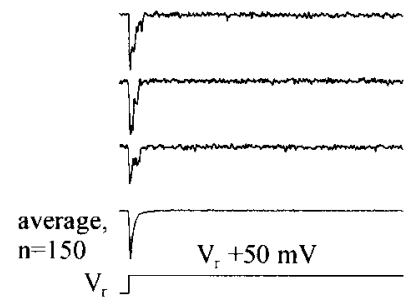

B control

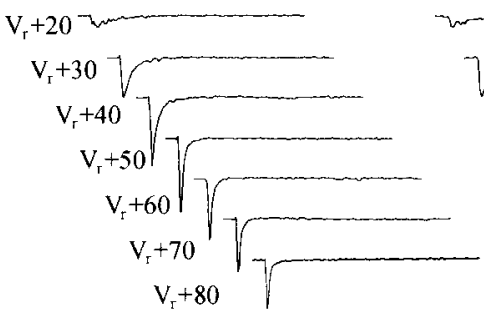

hypoxia, $4 \mathrm{~min}$

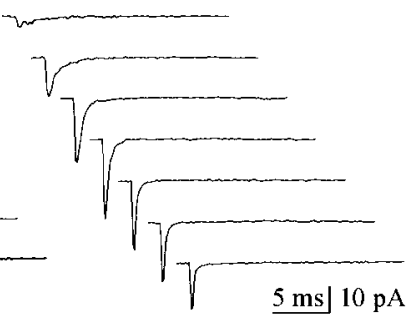

$\mathrm{C}$

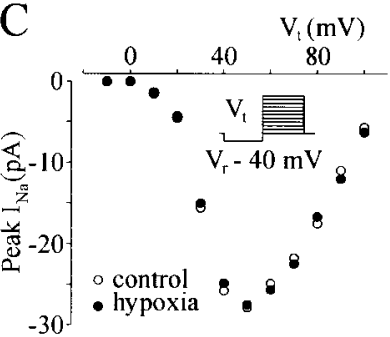

hypoxia, 4 min

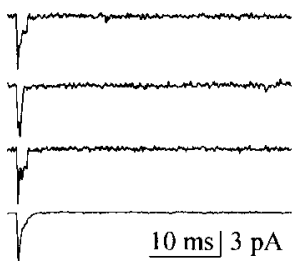

$\mathrm{D}$

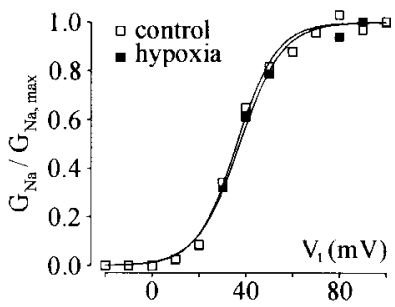

Figure 2. Early hypoxia does not affect the $\mathrm{Na}^{+}$channel kinetics. $A, \mathrm{Na}^{+}$ channel currents during $40 \mathrm{msec}$ depolarizing pulses to a $V_{\mathrm{r}}+50 \mathrm{mV}$ from a holding potential of $V_{\mathrm{r}}$ before and after a $4 \mathrm{~min}$ hypoxic episode. Currents were recorded in a cell-attached configuration from a representative layer 5 neuron in a $400-\mu \mathrm{m}$-thick slice at $37^{\circ} \mathrm{C}$. Bottom traces are ensemble $\mathrm{Na}^{+}$currents obtained by averaging 150 sweeps under each condition. $B$, Ensemble $\mathrm{Na}^{+}$currents from a different neuron at different membrane potentials in the control and after 4 min of hypoxia. The patch membrane was held at a $V_{\mathrm{r}}-40 \mathrm{mV}$ and stepped to a given test voltage for $20 \mathrm{msec}$ (see inset for $C$ ). Here and in $A$, currents were filtered at 3.5 $\mathrm{kHz}(-3 \mathrm{~dB})$ and digitized at $20 \mathrm{kHz}$. Note that 4 min of hypoxia did not alter the availability and properties of $\mathrm{Na}^{+}$channels. The $\mathrm{Na}^{+}$current $I-V$ curve $(C)$ and its conductance transform $(D)$ are not altered by hypoxia.

dialyzed with solution containing $\mathrm{K}$ gluconate $\left(\mathrm{E}_{\mathrm{Cl}-}=-70 \mathrm{mV}\right)$ and were held at a potential of approximately $-70 \mathrm{mV}$ by applying a small depolarizing or hyperpolarizing current. Under normoxic conditions, sEPSPs were seen as upward membrane potential deflections with an amplitude of $0.5-5 \mathrm{mV}$ and a frequency of $\sim 10 \mathrm{~Hz}$ (Fig. $3 A$ ). Induction of hypoxia resulted in a considerable increase in the frequency of sEPSPs within 15-20 sec (Fig. 3B). Although most sEPSPs during the very early stage of hypoxia were of small amplitude, probably reflecting a quantal glutamate release in single synaptic boutons, the frequency of largeamplitude synaptic events, which sometimes reached spike threshold, was also increased (Fig. $3 B$ ). Later in hypoxia, these large sEPSPs disappeared, and the amplitude of the rest of the events declined progressively (Fig. $3 C$ ), in parallel with a decrease in neuronal input resistance. After 3 min of hypoxia, while neuronal input resistance decreased by $60 \pm 14 \%$ from the mean prehy-
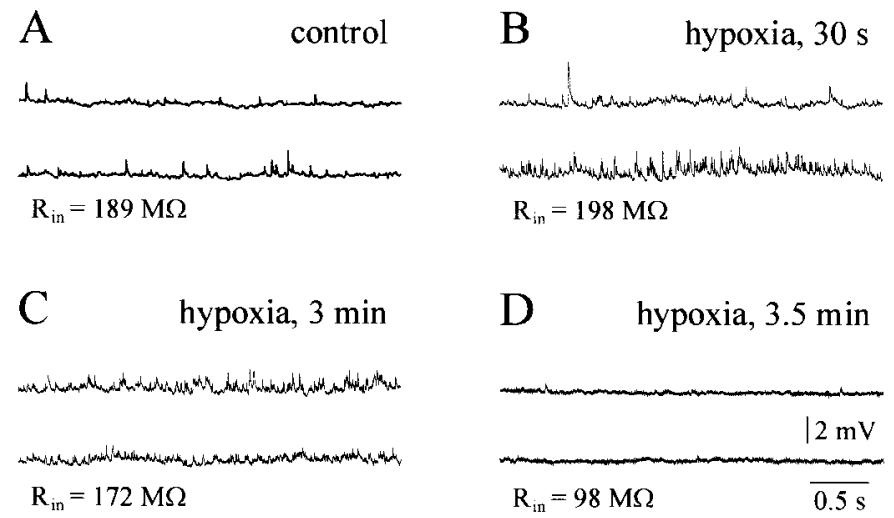

D hypoxia, $3.5 \mathrm{~min}$

$\frac{\mid 2 \mathrm{mV}}{\mathrm{R}_{\mathrm{in}}=98 \mathrm{M} \Omega}$

Figure 3. Hypoxia causes a rapid transient increase in the frequency of spontaneous EPSPs. $A$, A whole-cell current-clamp recording of sEPSPs from a representative layer 5 neuron under normoxic conditions. The cell was dialyzed with $\mathrm{K}$ gluconate-based solution $\left(\mathrm{E}_{\mathrm{Cl}}=-70 \mathrm{mV}\right)$ and held at voltage of approximately $-70 \mathrm{mV}$ with an injection of a small depolarizing current. $B$, Hypoxia within seconds markedly increases the frequency of spontaneous EPSPs. $C$, Starting from the second minute of hypoxia, the high-amplitude sEPSPs disappear; the frequency of the rest of the spontaneous events additionally increases. Note that the sEPSP amplitudes become progressively smaller, in parallel with decrease in neuronal input resistance. $D$, From the third minute of hypoxia, the sEPSPs become completely unresolvable from the noise.

poxic value of $191 \pm 88 \mathrm{M} \Omega(n=7$ cells $)($ Fig. $1 F)$, the individual sEPSPs became completely undistinguishable from noise (Fig. $3 D$ ). With reoxygenation, sEPSPs quickly reappeared, yet at a somewhat lower frequency than before hypoxia. It usually took $\sim 10$ min until the frequency of sEPSPs returned to the prehypoxic value. A biphasic effect of hypoxia on sEPSPs, similar to that shown in Figure 3, was observed in six additional neurons.

\section{Hypoxia enhances the frequency of spontaneous EPSCs}

From the above experiment, we conclude that the initial effect of hypoxia on spontaneous excitatory events is an enhancement of frequency followed by a reduction in amplitude. In seven neurons voltage-clamped at $-70 \mathrm{mV}$ and recorded with $\mathrm{Cs}^{+}$-filled electrodes, we examined the effect of hypoxia on the amplitudes and frequency of sEPSCs (Fig. 4). While being dialyzed with $\mathrm{Cs}^{+}$ ions, the neocortical neurons showed no significant change in the holding current at $-70 \mathrm{mV}$ during the first 4 min of hypoxia, apparently because $\mathrm{Cs}^{+}$ions block the potassium conductances that are primarily responsible for hypoxia-induced alterations in leakage ( $n=7$ cells; data not shown). In the representative neuron of Figure 4, the frequency of sEPSCs was already clearly increased $30 \mathrm{sec}$ after the onset of hypoxia (Fig. 4B). As in the case of the current-clamp sEPSP recordings (Fig. 3), there was enhancement of the frequencies of large-amplitude events, which presumably are action potential-dependent, and small-amplitude events, which presumably are action potential-independent. Thus, at $30 \mathrm{sec}$ from the beginning of the hypoxic episode, the frequency of sEPSCs with peak amplitudes of $>30 \mathrm{pA}$ increased on average by $66 \pm 16 \%$ ( $n=7$ cells), and the frequency of smaller sEPSCs was increased by $32 \pm 6 \%(n=7)$. As the hypoxia continued, the small-amplitude currents did not disappear, but their frequency continued to increase (Fig. 4C). After 3 min of hypoxia, these small-amplitude currents occurred at a frequency that was increased by $108 \pm 19 \%(n=7)$ in comparison with the control. However, large-amplitude events disappeared completely after $\sim 120 \mathrm{sec}$ of hypoxia (Fig. $4 C$ ). With reoxygenation, the 
A

control

B

|

C

hypoxia, $3 \mathrm{~min}$

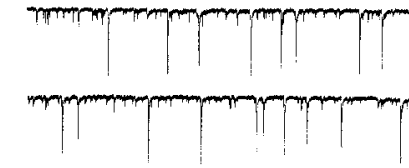

D reoxygenation, $2 \mathrm{~min}$

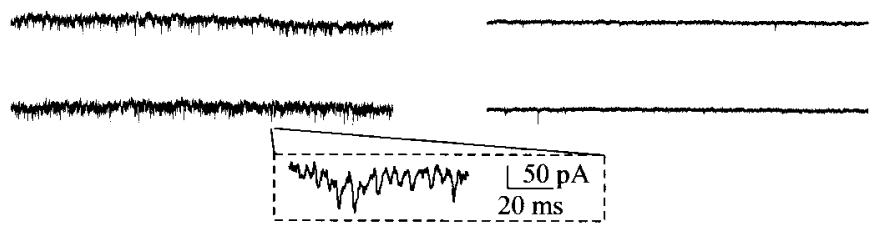

Figure 4. In a neuron dialyzed with $\mathrm{Cs}^{+}$ions, hypoxia causes a rapid and monotonic increase in sEPSC frequency. $A$, Voltage-clamp traces obtained with a Cs gluconate-containing pipette from a representative layer 5 neuron held at $-70 \mathrm{mV}$ under normoxic conditions. $B$, Thirty seconds after the onset of hypoxia, the frequency of sEPSCs increases; highamplitude events are seen frequently. $C$, At the third minute of hypoxia, the high-amplitude sEPSCs disappear; the frequency of the rest of the spontaneous events additionally increases. Note that dialyzing neurons with $\mathrm{Cs}^{+}$ions prevents a hypoxia-induced decrease in input resistance. Inset, A $100 \mathrm{msec}$ segment of the record at an extended time scale to show the individual, superimposed sEPSCs. $D$, Reoxygenation rapidly suppresses the frequency of sEPSCs beyond the prehypoxic value.

frequency of spontaneous events fell immediately, so that by 30 sec after the onset of reoxygenation it was $56 \pm 3 \%$ lower than in the control $(n=4)$. The sEPSC frequency remained depressed for $\sim 10 \mathrm{~min}$ and ultimately returned to control values. The differences in sEPSC frequency between the control, hypoxia, and reoxygenation were all statistically significant $(p<0.05)$.

\section{Hypoxia-induced enhancement in sEPSC frequency persists in both tetrodotoxin-containing and $\mathrm{Ca}^{2+}$-free bath solution}

The above experiment led us to conclude that the hypoxiainduced increase in neurotransmitter release is persistent, not transient, and that it becomes hidden in current-clamp recordings from $\mathrm{K}^{+}$dialyzed neocortical neurons by the decrease in neuronal input resistance.

Hypoxia primarily affects the frequency of low-amplitude sEPSPs and sEPSCs, most of which may be miniature events that do not depend on presynaptic action potentials and $\mathrm{Ca}^{2+}$ entrance (for review, see Katz, 1969; Edwards, 1995). To confirm that hypoxia does indeed increase the frequency of these miniature synaptic events, we repeated the above experiments in the presence of TTX and in nominally calcium-free aCSF. In Figure 5 , the averaged frequency of sEPSCs is plotted as a function of time. Figure $5 A$ shows the time course of hypoxia-induced alterations in sEPSC frequency in a representative neuron in a slice bathed in normal aCSF. As expected (Fig. 4), hypoxia induced a rapid and strong increase in sEPSC frequency that was quickly reversible, as well as undershooting with reoxygenation. In another neuron from a different slice preparation (Fig. $5 B$ ) that was preincubated in aCSF containing TTX $(1 \mu \mathrm{m})$, hypoxia produced a very similar effect on the frequency of sEPSCs. Removal of $\mathrm{Ca}^{2+}$ from aCSF (Fig. 5C) also did not significantly alter the magnitude and the time course of the hypoxia-induced increase in sEPSC frequency. At the end of a $3 \mathrm{~min}$ hypoxic episode, sEPSC frequency was enhanced by $44 \pm 8 \%(n=8)$ in the

presence of TTX and by $28 \pm 4 \%(n=6)$ in the $\mathrm{Ca}^{2+}$-free bath solution $(p<0.05)$.

Figure 6 shows the effect of brief hypoxia episodes on the amplitudes of sEPSCs in control aCSF, in the presence of TTX, and in the $\mathrm{Ca}^{2+}$-free bath solution. The cumulative amplitude histogram, based on measurement of the amplitudes of 500 sEPSCs under normoxic conditions in control aCSF (Fig. 6 $A$, open circles), shows that $\sim 20 \%$ of the synaptic events had amplitudes that were $>30 \mathrm{pA}$. These events most likely reflect a multibouton glutamate release synchronized by presynaptic action potentials, because they were completely absent in the presence of TTX (Fig. 6B, open circles), and in $\mathrm{Ca}^{2+}$-free bath solution (Fig. $6 C$, open circles). After $30 \mathrm{sec}$ of hypoxia (Fig. $6 \mathrm{~A}$, closed triangles), the relative frequency of sEPSCs with peak amplitudes of $>30 \mathrm{pA}$ was slightly decreased, despite the fact that these larger events were more frequent than in the normoxic control (Fig. 4B). This was because the rate of sEPSCs with amplitudes of $<30 \mathrm{pA}$ rose faster and predominated. At the third minute of hypoxia, all large-amplitude events disappeared (Fig. $6 A$, closed circles; Fig. $4 B$ ), and only the sEPSCs with amplitudes of $<30 \mathrm{pA}$ persisted.

In the presence of TTX (Fig. $6 B$ ) as well as in nominally $\mathrm{Ca}^{2+}$-free bath solution (Fig. $6 C$ ), hypoxia caused no alteration in the amplitudes of EPSCs. Qualitatively similar results were obtained in seven cells from slices bathed in control aCSF, in seven cells in the presence of TTX, and in six cells in $\mathrm{Ca}^{2+}$-free bath solution.

In four of the cells that were exposed to 4 min of hypoxia in the presence of TTX, there was no significant alteration in the decay of sEPSC (data not shown; $p>0.05$ ), indicating that the properties of postsynaptic glutamatergic receptors at this stage of hypoxia are not yet affected.

\section{Hypoxia enhances spontaneous IPSC frequency in a similar manner}

Figure 7 illustrates experiments designed to determine whether hypoxia has a similar effect on GABAergic synapses. To study spontaneous IPSCs (sIPSCs) in isolation, the neurons were dialyzed with $\mathrm{Cs}^{+}$gluconate and were voltage-clamped to $0 \mathrm{mV}$, the reversal potential of the EPSCs. Figure 7 shows sample recordings of sIPSCs before, during, and after hypoxia for a representative layer 5 neuron. As with sEPSCs (Fig. 5), the frequency of sIPSCs was already clearly increased $30 \mathrm{sec}$ after the onset of hypoxia (Fig. 7B). While hypoxia proceeded, the frequency of small-amplitude events continued to increase (Fig. 7C). After 3 min of hypoxia, these events occurred at a frequency that was $90 \pm 27 \%(n=7)$ higher than the control. However, largeamplitude events became rarer after $\sim 2$ min of hypoxia. After reoxygenation, the frequency of spontaneous events fell immediately to the prehypoxic value. The differences in sIPSC frequency between the control and hypoxia were all statistically significant $(p<0.05)$.

Figure 8 shows that the magnitude and the time course of the hypoxia-induced increase in sIPSC frequency did not differ in slices preincubated with $1 \mu \mathrm{m}$ TTX (Fig. $8 B$ ) and in $\mathrm{Ca}^{2+}$-free bath solution (Fig. $8 C$ ) compared with those bathed in normal aCSF (Fig. 8A). Similar results were obtained in recordings of sIPSC frequency from seven neurons in control aCSF, from five neurons in the presence of TTX, and from six neurons in the absence of $\mathrm{Ca}^{2+}$ ions. In three cells that were exposed to hypoxia in the presence of TTX, there was no significant alteration in the sIPSC decay time course after 4 min of hypoxia (data not shown; 

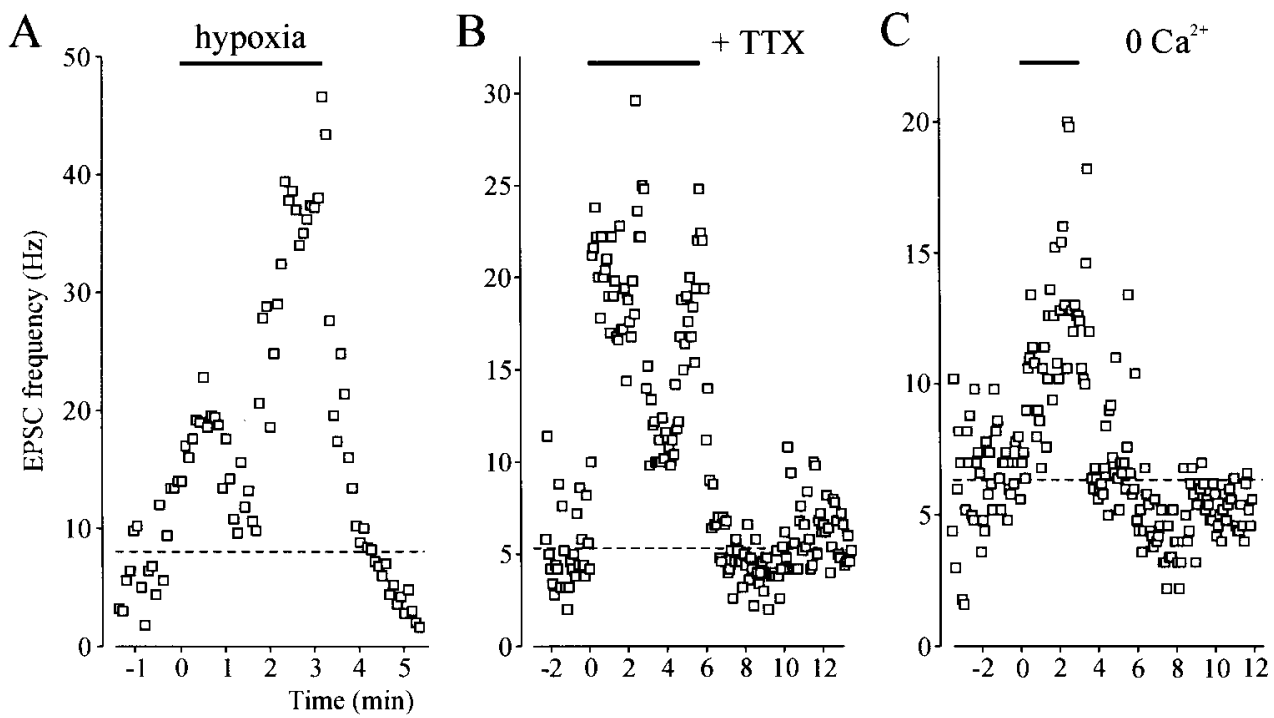

Figure 5. Hypoxia enhances miniature, $\mathrm{Ca}^{2+}$-independent, TTX-insensitive excitatory synaptic release. $A$, Plot of the frequency of sEPSCs as a function of time before, during, and after hypoxia. Each square represents an averaged sEPSC frequency during $5 \mathrm{sec}$. A dashed line represents an average sEPSC frequency during the prehypoxic period. The effect of hypoxia on sEPSC frequency persists in the presence of $1 \mathrm{~mm}$ TTX $(B)$ and when slices are bathed in nominally $\mathrm{Ca}^{2+}$-free solution $(C)$.
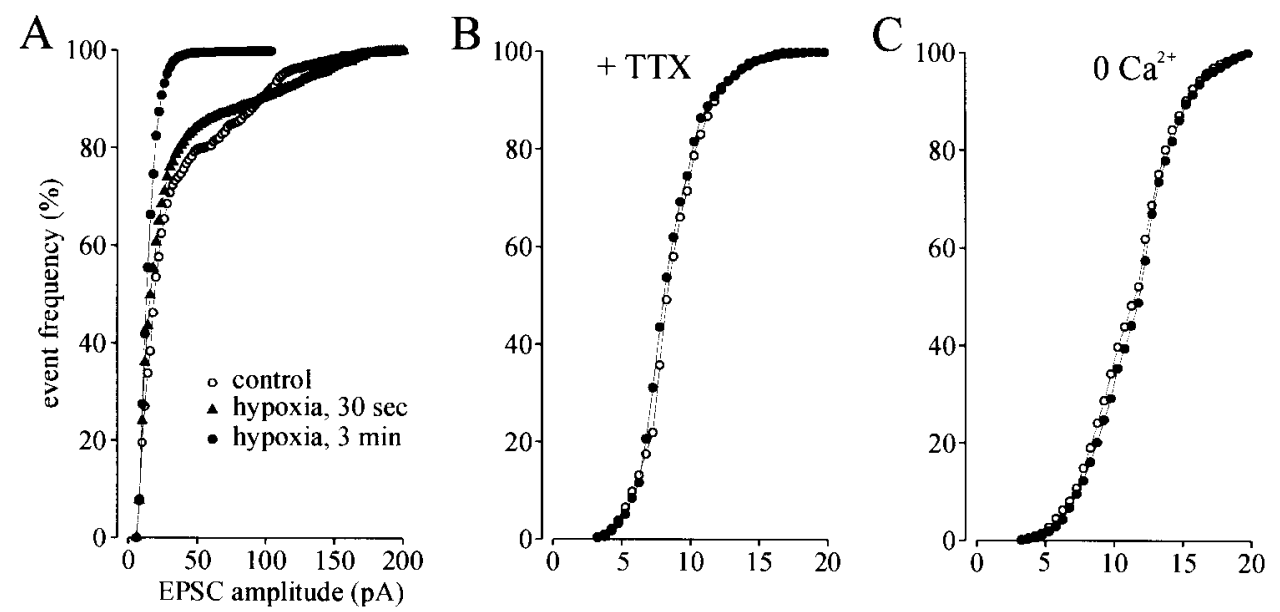

Figure 6. Effect of hypoxia on sEPSC amplitudes. $A$, The relative frequency of large-amplitude, action potentialdependent EPSCs transiently increases within a minute from the beginning of a hypoxic episode (closed triangles) compared with the normoxic control (open circles). Later, the large EPSCs disappear, leaving only small-amplitude $(<20 \mathrm{pA})$, action potential-independent events (closed circles). In the presence of TTX $(B)$ and in $\mathrm{Ca}^{2+}$-free perfusate $(C)$, hypoxia induces no change in EPSC amplitudes.

$p>0.05)$, indicating that the properties of the postsynaptic GABAergic receptors were not affected by the hypoxia.

\section{DISCUSSION}

The very rapid onset of the behavioral changes induced by impaired cerebral circulation (Rossen et al., 1943) must parallel a similarly rapid disruption of one or more of the cellular mechanisms that underlie normal cortical function. Although it is possible that the consequences of hypoxia are attributable to a direct sensitivity to oxygen molecules (Jiang and Haddad, 1994; Hammarstrom and Gage, 2000), it is much more likely that they reflect disrupted oxidative metabolism (for review, see Lipton, 1999).

Our results demonstrate that in the neocortex, the earliest hypoxia-triggered event relevant to neocortical circuit function is a profound increase in vesicular neurotransmitter release. The study was performed in an in vitro neocortical slice preparation, which allowed us to investigate the effects of hypoxia under well controlled experimental conditions and to implement in full the patch-clamp technique to examine both intrinsic neuronal conductances and synaptic transmission. To remove possible doubts about the $\mathrm{Q}_{10}$ of the different processes in the range between room temperature and $37^{\circ} \mathrm{C}$ (Stys et al., 1992; Dirig et al., 1997; Ransom et al., 2000), all experiments, including cell-attached single-channel recordings, were done at physiological temperatures. We considered the possibility that some of the hypoxia-

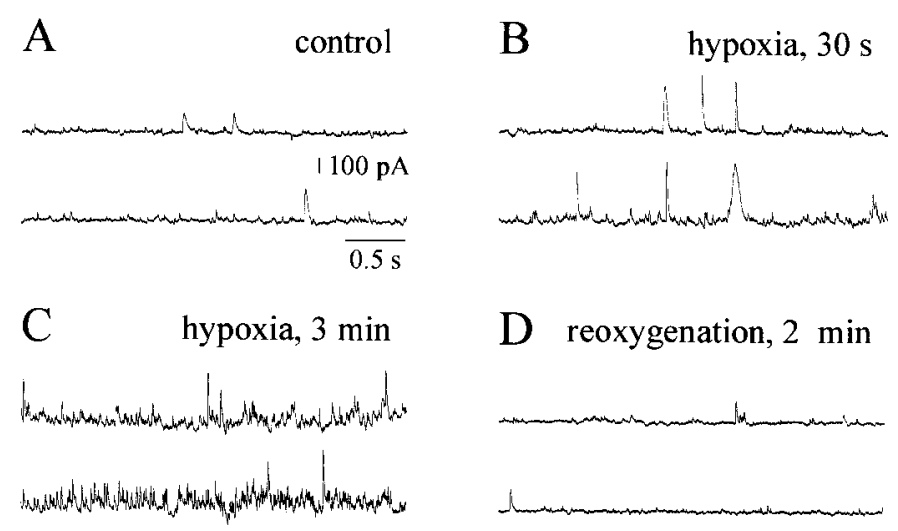

Figure 7. The frequency of spontaneous IPSCs also increases during hypoxia. $A$, Voltage-clamp traces obtained with a Cs gluconate-containing pipette from a representative layer 5 neuron held at $0 \mathrm{mV}$ under normoxic conditions. $B$, Thirty seconds after the onset of hypoxia, the frequency of sIPSCs increases; high-amplitude events are seen frequently. $C$, At the third minute of hypoxia, the high-amplitude sIPSCs disappear; the frequency of the rest of the spontaneous events additionally increases. $D$, Reoxygenation rapidly decreases the frequency of sIPSCs. 


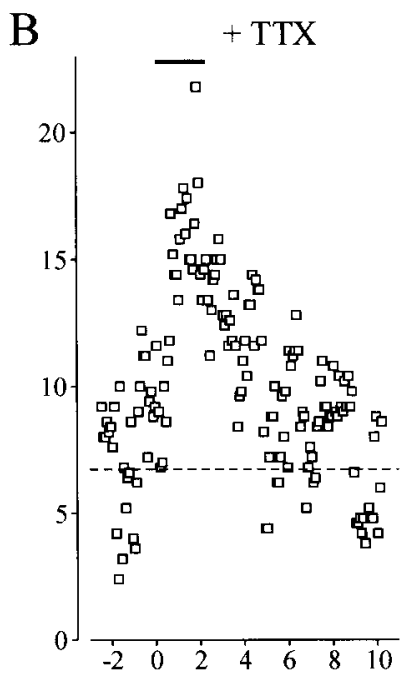

Figure 8. Hypoxia-induced increase in sIPSC frequency persists in $\mathrm{Ca}^{2+}$-free bath solution. $A$, Plot of the frequency of sIPSCs as a function of time before, during, and after hypoxia. Each square represents an averaged SIPSC frequency during $5 \mathrm{sec}$. A dashed line represents an average sIPSC frequency during the prehypoxic period. The effect of hypoxia on sIPSC frequency persists in the presence of $1 \mu \mathrm{m}$ of TTX $(B)$ and when slices are bathed in nominally $\mathrm{Ca}^{2+}$-free solution $(C)$.

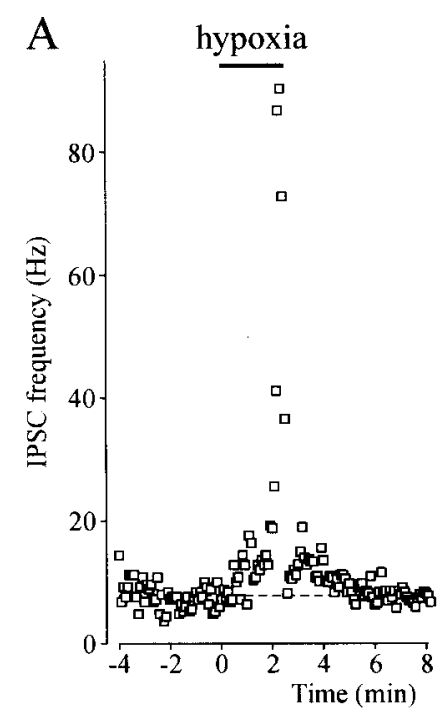

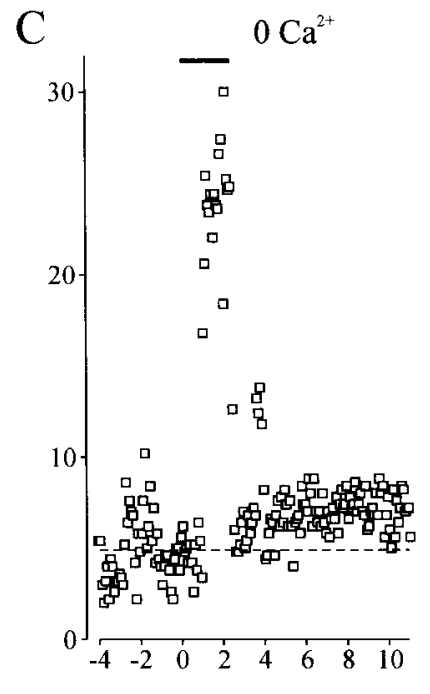

induced changes observed in whole-cell recordings might be exaggerated by dialyzing the neuron with ATP-free media, whereas others might be slowed or completely prevented by washing in powerful $\mathrm{H}^{+}$and $\mathrm{Ca}^{2+}$ buffers. In the present study, however, the effects of oxygen deprivation on $\mathrm{K}^{+}$and $\mathrm{Na}^{+}$ channel activities were evaluated using the cell-attached configuration of the patch-clamp technique, which does not require rupture of the membrane and therefore does not interfere with "naturally" occurring disturbances in cytosolic content. Moreover, the observed time course of the increase in frequency of PSCs, although studied in whole-cell recordings, was also not influenced by the recording method, because it reflected an effect of hypoxia on the undialyzed presynaptic terminals.

We held slices in an interface-type chamber and produced hypoxia by switching the surrounding gas mixture to one that was oxygen-free. This has been reported to be the in vitro method for tissue maintenance and hypoxia induction that most closely replicates the changes observed in the hypoxic brain in vivo (Croning and Haddad, 1998). There are differences, however. Because oxygen consumption in the relatively quiescent brain slice is lower than in the neocortex in vivo (Raichle, 1998; Schurr et al., 1999), and the average distance for oxygen diffusion through the slicegas mixture interface is larger than that between neurons and capillaries (Reina-De La Torre et al., 1998), the very rapid sequence of events that we observed after hypoxia in vitro may transpire even faster in the brain when circulation is compromised. Thus, the increase in spontaneous neurotransmitter release that we observed in slices 15-30 sec after hypoxia onset would probably begin almost instantly in a behaving animal after a critical decrease in oxygenated blood supply.

Earlier whole-cell studies in dissociated neocortical neurons (Cummins et al., 1993), in hippocampal neurons (O'Reilly et al., 1997), and in brainstem neurons in slices (Mironov and Richter, 1999) ascribed the earliest behavioral effect of hypoxia to a decreased availability of $\mathrm{Na}^{+}$channels and a resulting decrease in neuronal excitability. For reasons that we do not understand, we, like Hammarstrom and Gage (1998), did not see any consistent change in the transient $\mathrm{Na}^{+}$current during the first 4 min after the onset of hypoxia, although our experiments were performed at physiological temperatures, and we did observe changes in synaptic currents and in the opening probability of $\mathrm{K}_{\mathrm{ATP}}$ channels in the same slices at earlier times after onset of the hypoxic episode.

Our data are consistent with the reports of several investigators that hypoxia is associated with a decrease in apparent input resistance (Luhmann and Heinemann, 1992; Zhang and Krnjevic, 1993; Jiang et al., 1994; Fujimura et al., 1997), which is primarily attributed to an increase in activation of the ATPsensitive $\mathrm{K}^{+}$conductance. Our rough estimates based on direct measurement of density, conductance, and the open probability of $\mathrm{K}_{\mathrm{ATP}}$ channels at the third minute of oxygen deprivation indicate that in neocortical neurons, as elsewhere, the activation of $\mathrm{K}_{\mathrm{ATP}}$ channels alone is enough to explain the hypoxia-induced decrease in input resistance, as seen in current-clamp whole-cell recordings. Thus, in a spherical cell with a diameter of $20 \mu \mathrm{m}$, the activation of $\mathrm{K}_{\mathrm{ATP}}$ channels that are present at a density of two channels $/ \mu \mathrm{m}^{2}$, have a single-channel conductance of $59 \mathrm{pS}$, and have an open probability of 0.15 would give rise to a shunting conductance of $\sim 20 \mathrm{nS}$, which is sufficient to decrease the neuronal input resistance to $\sim 20 \%$ of its control value. We propose, however, that other factors also contribute to the decrease in resistance of neocortical neurons. It is likely that the large increase in spontaneous bombardment of the postsynaptic membrane at both GABAergic and glutamatergic synapses (Figs. 4, 7), which precedes activation of potassium currents, is responsible for the initial increase in general neuronal conductance. Indeed, Salin and Prince (1996) showed that in neocortical neurons in slices held under normoxic conditions, blockade of the sIPSCs causes a decrease in resting conductance of $\sim 0.5 \mathrm{nS}$. A 10 -fold increase in SIPSC frequency, such as we observed in the neuron illustrated in Figure 7 after 2 min of hypoxia, would cause an increase in leakage to $5 \mathrm{nS}$ and thus lead to a decrease in input resistance to approximately half of its normoxic value. Interestingly, blockade of transmitter release by botulinum toxin A has been shown to prevent the increase in input conductance elicited by brief hypoxia in thalamocortical neurons in slices (Erdemli and Crunelli, 1998).

Evidence has been presented here that indicates that, in the neocortex, the earliest hypoxia-triggered event that might affect the neocortical circuit processing is an increase in miniature release of glutamate and GABA. The precise mechanism involved in augmented transmitter release remains unclear. Our 
finding that the increase in release frequency persists in the presence of TTX and with $\mathrm{Ca}^{2+}$-free bath solution indicates that this mechanism entails the presynaptic terminal itself and it is not dependent on $\mathrm{Ca}^{2+}$ entry from the extracellular space. Because both inhibitory and excitatory synapses were affected, we infer that the effect of oxygen deprivation was exerted at some stage in the general exocytotic process that is common to all presynaptic machinery, independent of the transmitter involved. A similar hypoxia-induced increase in the frequency of miniature synaptic events, which is also resistant to the removal of extracellular calcium, has been reported to occur at neuromuscular junctions (Hubbard and Loyning, 1966; Nishimura, 1986), in CA1 hippocampal neurons (Hershkowitz et al., 1993; Katchman and Hershkowitz, 1993), and in brainstem neurons (Kulik et al., 2000). Our data are also consistent with ultrastructural evidence of loss or clumping of synaptic vesicles in neocortical presynaptic endings very early during ischemia or hypoxia (Webster and Ames, 1965; Williams and Grossman, 1970). Recent electron microscopic evidence suggests that the exceptional sensitivity of central presynaptic terminals to hypoxia may reflect specific features of their energy metabolism. Three-dimensional reconstructions of axonal terminals in area CA3 of the hippocampus indicate that the high energy demands of the presynaptic terminals, which are necessary to maintain ionic gradients and to fuel synaptic vesicle cycling, often must be met by only a single mitochondria, which may be significantly separated from the energy utilization site by a long and narrow axonal shaft (Shepherd and Harris, 1998). The small volume of the axonal terminal, its isolation from the rest of the axon, and its high rate of energy consumption may render its energy metabolism and $\mathrm{Ca}^{2+}$ homeostasis particularly sensitive to changes in oxygen supply.

Whatever the mechanism for the hypoxia-induced changes at the synapse, these changes would be expected to markedly affect normal neocortical circuit function. An indiscriminate enhanced probability of miniature, action potential-independent transmitter release would affect action potential-dependent release, because the synaptic vesicles that are available for these processes are drawn from the same readily limited releasable pool (Rosenmund and Stevens, 1996), and both types of release are controlled by essential parts of a common release machinery (Capogna et al., 1997). Because normal processing by the neocortical circuit must entail precise timing of individual spikes and their postsynaptic consequences (Abeles et al., 1994; Softky, 1995; Victor and Purpura, 1996), the effects we observed after the onset of hypoxia would be expected to have a devastating effect on neocortical function, both by introducing incoherent noise and by disrupting normal neuronal integration of inputs.

Interestingly, the synaptic changes we observed were rapidly reversible, as were the behavioral consequences of arrest of cerebral circulation reported by Rossen et al. (1943). They found that consciousness was regained with 5-10 sec of re-establishing blood flow. It is important to note, however, that should the hypoxia persist, the consequent enhancement in the rate of transmitter release, which reflects a direct effect on presynaptic terminals, would also be expected to persist, although the somatic membrane is rendered relatively unexcitable by ATP- $\mathrm{K}^{+}$shunting conductance. Because most of the neocortical terminals are glutamatergic, this outpouring of transmitter could ultimately contribute to excitotoxicity caused by prolonged hypoxia (Lee et al., 2000).

\section{REFERENCES}

Abeles M, Prut Y, Bergman H, Vaadia E (1994) Synchronization in neuronal transmission and its importance for information processing. Prog Brain Res 102:395-404.

Blanton MG, Lo Turco JJ, Kriegstein AR (1989) Whole cell recording from neurons in slices of reptilian and mammalian cerebral cortex. J Neurosci Methods 30:203-210.

Capogna M, McKinney RA, O'Connor V, Gahwiler BH, Thompson SM (1997) $\mathrm{Ca}^{2+}$ or $\mathrm{Sr}^{2+}$ partially rescues synaptic transmission in hippocampal cultures treated with botulinum toxin $\mathrm{A}$ and $\mathrm{C}$, but not tetanus toxin. J Neurosci 17:7190-7202.

Croning MD, Haddad GG (1998) Comparison of brain slice chamber designs for investigations of oxygen deprivation in vitro. J Neurosci Methods 81:103-111.

Cummins TR, Jiang C, Haddad GG (1993) Human neocortical excitability is decreased during anoxia via sodium channel modulation. J Clin Invest 91:608-615.

Dirig DM, Hua XY, Yaksh TL (1997) Temperature dependency of basal and evoked release of amino acids and calcitonin gene-related peptide from rat dorsal spinal cord. J Neurosci 17:4406-4414.

Edwards FA (1995) Anatomy and electrophysiology of fast central synapses lead to a structural model for long-term potentiation. Physiol Rev 75:759-787.

Erdemli G, Crunelli V (1998) Response of thalamocortical neurons to hypoxia: a whole-cell patch-clamp study. J Neurosci 18:5212-5224.

Fleidervish IA, Friedman A, Gutnick MJ (1996) Slow inactivation of $\mathrm{Na}^{+}$current and slow cumulative spike adaptation in mouse and guinea-pig neocortical neurones in slices. J Physiol (Lond) 493:83-97.

Fleidervish IA, Binshtok AM, Gutnick MJ (1998) Functionally distinct NMDA receptors mediate horizontal connectivity within layer 4 of mouse barrel cortex. Neuron 21:1055-1065.

Fujimura N, Tanaka E, Yamamoto S, Shigemori M, Higashi H (1997) Contribution of ATP-sensitive potassium channels to hypoxic hyperpolarization in rat hippocampal CA1 neurons in vitro. J Neurophysiol 77:378-385.

Fujiwara N, Higashi H, Shimoji K, Yoshimura M (1987) Effects of hypoxia on rat hippocampal neurones in vitro. J Physiol (Lond) 384:131-151.

Haas HL, Schaerer B, Vosmansky M (1979) A simple perfusion chamber for the study of nervous tissue slices in vitro. J Neurosci Methods $1: 323-325$.

Hamill OP, Marty A, Neher E, Sakmann B, Sigworth FJ (1981) Improved patch-clamp techniques for high-resolution current recording from cells and cell-free membrane patches. Pflügers Arch 391:85-100.

Hammarstrom AK, Gage PW (1998) Inhibition of oxidative metabolism increases persistent sodium current in rat CA1 hippocampal neurons. J Physiol (Lond) 510:735-741.

Hammarstrom AK, Gage PW (2000) Oxygen-sensing persistent sodium channels in rat hippocampus. J Physiol (Lond) 529:107-118.

Hansen AJ, Hounsgaard J, Jahnsen H (1982) Anoxia increases potassium conductance in hippocampal nerve cells. Acta Physiol Scand 115:301-310.

Hara H, Sukamoto T, Kogure K (1993) Mechanism and pathogenesis of ischemia-induced neuronal damage. Prog Neurobiol 40:645-670.

Hershkowitz N, Katchman AN, Veregge S (1993) Site of synaptic depression during hypoxia: a patch-clamp analysis. J Neurophysiol 69:432-441.

Hubbard JI, Loyning Y (1966) The effects of hypoxia on neuromuscular transmission in a mammalian preparation. J Physiol (Lond) 185:205-223.

Jiang C, Haddad GG (1992) Differential responses of neocortical neurons to glucose and/or $\mathrm{O}_{2}$ deprivation in the human and rat. J Neurophysiol 68:2165-2173.

Jiang C, Haddad GG (1994) A direct mechanism for sensing low oxygen levels by central neurons. Proc Natl Acad Sci USA 91:7198-7201.

Jiang C, Sigworth FJ, Haddad GG (1994) Oxygen deprivation activates an ATP-inhibitable $\mathrm{K}^{+}$channel in substantia nigra neurons. J Neurosci 14:5590-5602.

Kandel ER, Schwartz JH (1985) Principles of neural science, Ed 2. New York: Elsevier.

Karschin C, Ecke C, Ashcroft FM, Karschin A (1997) Overlapping distribution of $\mathrm{K}_{\text {}}$, channel-forming Kir6.2 subunit and the sulfonylurea receptor SUR1 in rodent brain. FEBS Lett 401:59-64.

Katchman AN, Hershkowitz N (1993) Early anoxia-induced vesicular glutamate release results from mobilization of calcium from intracellular stores. J Neurophysiol 70:1-7.

Katz B (1969) The release of neural transmitter substances. Springfield, IL: Thomas.

Krnjevic K, Leblond J (1989) Changes in membrane currents of hippocampal neurons evoked by brief anoxia. J Neurophysiol 62:15-30.

Kulik A, Trapp S, Ballanyi K (2000) Ischemia but not anoxia evokes vesicular and $\mathrm{Ca}^{2+}$-independent glutamate release in the dorsal vagal complex in vitro. J Neurophysiol 83:2905-2915. 
Leblond J, Krnjevic K (1989) Hypoxic changes in hippocampal neurons. J Neurophysiol 62:1-14.

Lee JM, Grabb MC, Zipfel GJ, Choi DW (2000) Brain tissue responses to ischemia. J Clin Invest 106:723-731.

Lipton P (1999) Ischemic cell death in brain neurons. Physiol Rev 79:1431-1568.

Luhmann HJ, Heinemann U (1992) Hypoxia-induced functional alterations in adult rat neocortex. J Neurophysiol 67:798-811.

Mironov SL, Richter DW (1999) Cytoskeleton mediates inhibition of the fast $\mathrm{Na}^{+}$current in respiratory brainstem neurons during hypoxia. Eur J Neurosci 11:1831-1834.

Mourre C, Ben Ari Y, Bernardi H, Fosset M, Lazdunski M (1989) Antidiabetic sulfonylureas: localization of binding sites in the brain and effects on the hyperpolarization induced by anoxia in hippocampal slices. Brain Res 486:159-164.

Nishimura M (1986) Factors influencing an increase in spontaneous transmitter release by hypoxia at the mouse neuromuscular junction. J Physiol (Lond) 372:303-313.

O'Reilly JP, Cummins TR, Haddad GG (1997) Oxygen deprivation inhibits $\mathrm{Na}^{+}$current in rat hippocampal neurones via protein kinase $\mathrm{C}$. J Physiol (Lond) 503:479-488.

Pelletier MR, Pahapill PA, Pennefather PS, Carlen PL (2000) Analysis of single $\mathrm{K}_{\text {(ATP }}$ channels in mammalian dentate gyrus granule cells. J Neurophysiol 84:2291-2301.

Raichle ME (1998) Behind the scenes of functional brain imaging: a historical and physiological perspective. Proc Natl Acad Sci USA 95:765-772.

Ransom CB, Ransom BR, Sontheimer H (2000) Activity-dependent extracellular $\mathrm{K}^{+}$accumulation in rat optic nerve: the role of glial and axonal $\mathrm{Na}^{+}$pumps. J Physiol (Lond) 522:427-442.

Reina-De La Torre F, Rodriguez-Baeza A, Sahuquillo-Barris J (1998) Morphological characteristics and distribution pattern of the arterial vessels in human cerebral cortex: a scanning electron microscope study. Anat Rec 251:87-96.
Rosenmund C, Stevens CF (1996) Definition of the readily releasable pool of vesicles at hippocampal synapses. Neuron 16:1197-1207.

Rossen R, Kabat H, Anderson JP (1943) Acute arrest of cerebral circulation in man. Arch Neurol Psychiatry 50:510-528.

Salin PA, Prince DA (1996) Spontaneous GABA receptor-mediated inhibitory currents in adult rat somatosensory cortex. J Neurophysiol 75:1573-1588.

Schurr A, Payne RS, Miller JJ, Rigor BM (1999) Study of cerebral energy metabolism using the rat hippocampal slice preparation. Methods 18:117-126.

Shepherd GM, Harris KM (1998) Three-dimensional structure and composition of CA3-CA1 axons in rat hippocampal slices: implications for presynaptic connectivity and compartmentalization. J Neurosci 18:8300-8310.

Softky WR (1995) Simple codes versus efficient codes. Curr Opin Neurobiol 5:239-247.

Stys PK, Waxman SG, Ransom BR (1992) Effects of temperature on evoked electrical activity and anoxic injury in CNS white matter. J Cereb Blood Flow Metab 12:977-986.

Victor JD, Purpura KP (1996) Nature and precision of temporal coding in visual cortex: a metric-space analysis. J Neurophysiol 76:1310-1326.

Webster HF, Ames A (1965) Reversible and irreversible changes in the fine structure of nervous tissue during oxygen and glucose deprivation. J Cell Biol 26:885-908.

Williams V, Grossman RG (1970) Ultrastructure of cortical synapses after failure of presynaptic activity in ischemia. Anat Rec 166:131-141.

Xia Y, Haddad GG (1991) Major differences in CNS sulfonylurea receptor distribution between the rat (newborn, adult) and turtle. J Comp Neurol 314:278-289.

Young JN, Somjen GG (1992) Suppression of presynaptic calcium currents by hypoxia in hippocampal tissue slices. Brain Res 573:70-76.

Zhang L, Krnjevic K (1993) Whole-cell recording of anoxic effects on hippocampal neurons in slices. J Neurophysiol 69:118-127. 